\title{
Editorial: Emerging Concerns, Biology and Conservation in Key Marine Environments Undergoing Highly Selective Pressures
}

\author{
Rachel Ann Hauser-Davis ${ }^{1 *}$ and Salvatore Siciliano ${ }^{2}$ \\ 'Laboratório de Avaliação e Promoção da Saúde Ambiental, Instituto Oswaldo Cruz (Fiocruz), Rio de Janeiro, Brazil, \\ ${ }^{2}$ Fundação Oswaldo Cruz (Fiocruz), Rio de Janeiro, Brazil
}

Keywords: conservation, anthropogenic activities, coastal environments, pressures, degradation

Editorial on the Research Topic

OPEN ACCESS

Edited and reviewed by: Laura Airoldi,

University of Padova Chioggia

Hydrobiological Station, Italy

*Correspondence:

Rachel Ann Hauser-Davis

rachel.hauser.davis@gmail.com

Specialty section:

This article was submitted to

Marine Conservation and

Sustainability,

a section of the journal

Frontiers in Marine Science

Received: 09 August 2021

Accepted: 20 August 2021

Published: 10 September 2021

Citation:

Hauser-Davis RA and Siciliano S (2021) Editorial: Emerging Concerns,

Biology and Conservation in Key Marine Environments Undergoing

Highly Selective Pressures.

Front. Mar. Sci. 8:755991.

doi: 10.3389/fmars.2021.755991
Emerging Concerns, Biology and Conservation in Key Marine Environments Undergoing Highly Selective Pressures

Motivated by the increasing effects of anthropogenic activities and habitat degradation on the biodiversity of endangered marine species, this Special Topic in Frontiers in Marine Science explores worldwide topics of interest, bringing forth new points of view on global issues and addressing the increasing concerns regarding several key issues in this field, such as fisheries by-catch, chemical contamination, and conservation actions required to mitigate these impacts.

The motivation for our decision to produce such a Special Topic is the profound state of degradation that many marine ecosystems are suffering worldwide. Overfishing, pollution, and coastal occupation ae causing many marine ecosystems to collapse, and an urge for local actions may be the driver to change this scenario. Science and education are key in solving this urgent question.

Readers will find an integrated discussion on this subject, focusing on both general concepts and specific issues of major biological groups, extending beyond conventional systems. Among many valuable manuscripts, outstanding studies were selected and are compiled in this issue. Aspects on species still lacking data, mainly from the Neotropics, along with localized action that may be applied in a global manner in different habitats and areas, are discussed in detail. Dr. Salvatore Siciliano and I, Dr. Rachel Ann Hauser-Davis, were honored by the Editor-in-chief's invitation to edit this issue and we would like to thank all authors for their support and confidence. We hope that this content contributes to the improvement of the biology and conservation efforts in key marine environments known as undergoing highly selective pressures, such as coastal environments, tropical lagoons, salt marshes, estuaries and rivers, either physical (noise, significant alterations though port constructions, dredging), chemical (increased contaminant levels) or physicochemical (water, sediment), 
and highlights the usefulness of these assessments in a unified approach.

\section{AUTHOR CONTRIBUTIONS}

All authors listed have made a substantial, direct and intellectual contribution to the work, and approved it for publication.

Conflict of Interest: The authors declare that the research was conducted in the absence of any commercial or financial relationships that could be construed as a potential conflict of interest.
Publisher's Note: All claims expressed in this article are solely those of the authors and do not necessarily represent those of their affiliated organizations, or those of the publisher, the editors and the reviewers. Any product that may be evaluated in this article, or claim that may be made by its manufacturer, is not guaranteed or endorsed by the publisher.

Copyright (C) 2021 Hauser-Davis and Siciliano. This is an open-access article distributed under the terms of the Creative Commons Attribution License (CC BY).

The use, distribution or reproduction in other forums is permitted, provided the original author(s) and the copyright owner(s) are credited and that the original publication in this journal is cited, in accordance with accepted academic practice. No use, distribution or reproduction is permitted which does not comply with these terms. 